\title{
Total methane content in the atmosphere of Western Siberia in 2000-2020 according to the data of chemical transport model MOZART-4
}

\author{
Egor Yu. Mordvin ${ }^{1,2}$, Anatoly A. Lagutin ${ }^{1,2}$ and Nikolay V. Volkov ${ }^{1,2}$ \\ ${ }^{1}$ Altai State University, Barnaul, Russia \\ ${ }^{2}$ Federal Research Center for Information and Computational Technologies, Novosibirsk, Russia
}

\begin{abstract}
The paper considers the behavior of total methane content in the atmosphere of Western Siberia obtained using the global chemical transport model MOZART-4 (Model for OZone And Related chemical Tracers, version 4). We discuss details of the model configuration for simulation of methane content until the end of the XXI century within the Representative Concentration Pathways (RCP4.5 and RCP8.5). Boundary conditions at the lower levels of the model (methane content in the surface air layer) was obtained using data from the Earth System Research Laboratories (ESRL) project and the results of the Atmospheric Chemistry-Transport Models (ACTM) for 2007-2010. The methane content in the stratosphere was also defining according to the ACTM results. The climate data used in MOZART- 4 is based on the results of the Goddard Earth Observing System, Version 5 (GEOS-5). The modification of the boundary conditions carried out in the work made it possible to reproduce the summer and winter maximum in the annual course of $\mathrm{CH}_{4}$. These results are confirmed by satellite and aircraft observations made on the territory of Western Siberia. It was found that the total methane content in the atmosphere of the studied region (45-65 N, 60-90 E) in 2000-2020 increased with a trend of about $3.5 \pm 0.2 \mathrm{ppb}$ /year. In 2000-2006, there is virtually no trend. The increase of $\mathrm{CH}_{4}$ in 2007-2020 has a trend of $\sim 5.0 \pm 0.2 \mathrm{ppb} /$ year. The global data obtained as a result of the simulation can be used as initial and boundary conditions of the chemical version of the regional climate model RegCM-CHEM4.
\end{abstract}

Keywords

Western Siberia, atmosphere methane, total methane content, MOZART-4, modification of the boundary conditions.

\section{Introduction}

Over the past 270 years, the amount of methane in the atmosphere has increased by about $253 \%$ and currently amounts to about $1872 \pm 2 \mathrm{ppb}$ [1]. The increase of methane concentration is associated with the increasing rates of industrial and agricultural production [2]. Also, in the course the last 30-50 years an increase in the average annual temperature [3] has been leading to the melting of vast permafrost areas. In this regard, such territories are transformed into new wetland complexes $[4,5]$, which, in turn, make an additional contribution to methane emissions. This positive feedback effect is called the methane catastrophe.

SDM-2021: All-Russian conference, August 24-27, 2021, Novosibirsk, Russia

Ðzion0210@gmail.com (E.Yu. Mordvin); lagutin@theory.asu.ru (A. A. Lagutin); volkov@theory.asu.ru

(N. V. Volkov)

(D) 0000-0001-9327-100X (E. Yu. Mordvin); 0000-0002-1814-8041 (A. A. Lagutin); 0000-0002-3172-0655 (N. V. Volkov)

(c) (i) $\odot 2021$ Copyright for this paper by its authors. Use permitted under Creative Commons License Attribution 4.0 International (CC BY 4.0).

$[\mathrm{m}$ 
The direct and indirect contribution of anthropogenic radiation exposure of atmospheric methane is estimated at $0.7 \mathrm{~W} / \mathrm{m}^{2}$, or about half of $\mathrm{CO}_{2}$ contribution [6]. This large contribution of methane into climate change makes it an important component of the Earth's atmosphere. It's necessary to assess how methane is emitted into the atmosphere and sinks from it, as well as how it affects to the atmospheric processes in a long time perspective [7].

Studies aimed at describing the behavior of methane are based on a large amount of groundbased observations and satellite data. However, simulations describing chemical interactions between atmospheric components at the global and regional levels are of great interest [3]. The increase of the methane content and other small gas components of the atmosphere established since the beginning of the industrial era [4] has become a trigger for creating a large number of scenarios [5] of the global climate system evolution, where the predictor is represented by a change of the greenhouse gases concentration. One of the most important directions of such research is the searching for sources of greenhouse gases [6], as well as the numerical assessment of their emissions.

The aim of the work is to simulate the behavior of the total methane content in the atmosphere of Western Siberia in 2000-2020 using the MOZART-4 chemical transport model.

\section{MOZART-4 model}

The global chemical transport model MOZART (Model for OZone And Related chemical Tracers) was developed with the participation of National Center for Atmospheric Research (NCAR), USA, Geophysical Fluid Dynamics Laboratory (GFDL), USA, and Max Planck Institute for Meteorology (MPI-Met), Germany, for modeling tropospheric processes. Subsequent versions of the model made it possible to simulate the stratospheric and mesospheric processes [8].

MOZART-4 is a global tropospheric chemical transport model that includes several additions from the previous tropospheric version of the MOZART-2 model. The first version of the MOZART global tropospheric chemical transport model was presented in 1998. To date, four versions of the model have been developed. The MOZART model was built using several atmospheric modules of the Multi-scale Atmospheric Transport and Chemistry (MATCH). Convective mass fluxes detected by this model use the formulation of Hack for small and medium-level convective mass transfers [8]. Vertical diffusion within the boundary layer is based on the parameterization of Hollstlang and Beauville [8].

The model can be driven by almost any dataset and any emission inventory tool, so there is no standard modeling involved.

The latest version MOZART-4, like all previous versions, is an autonomous model that only needs meteorological data for the entire duration of the simulation.

The model in the basic version has the following configurations:

- spatial resolution is $2.8 \times 2.8^{\circ}$;

- 28 sigma-levels on vertical, from the Earth surface to a height of $2 \mathrm{hPa}$;

- includes 157 gas reactions, of these, 39 photolysis reactions for 85 types of gases and 12 aerosol components are presented;

- resolution of boundary conditions is $20 \times 20^{\circ}$. 
The model calculates the content of gas components by solving the mass conservation equation. Computation accounts for various types of transport (diffusion, advective and convective), the emission of each gas component from the underlying surface, aerosols, wet and dry deposition, and photochemical reactions.

A distinctive feature of MOZART-4 is the use of an open chemical preprocessor. The preprocessor allows user to update chemical rates, initiate new processes, or run models with a simplified chemistry mechanism. The model can also read autonomous components such as $\mathrm{OH}$ and chemical intermediates and losses, which allows simulations with relatively simple chemistry (such as $\mathrm{CO}$ or $\mathrm{CH}_{4}$ ) without running full chemistry. MOZART-4 can be launched with almost any resolution, depending on memory constraints and as consistent input meteorological fields [8].

MOZART-4 source code can be compiled, configured and run on personal computers using Linux or Unix operating systems with support from Portland Group, Lahey/Fujitsu compilers, or Intel Fortran 90 or 95 compiler, GNU Make utilities, and netCDF library. In this work, the assembly of the model in the latest revision was carried out using the GNU Fortran compiler.

The model can be built and run in single-threaded (Single) and several parallel modes (OpenMP, MPI or OpenMP+MPI). In the study, MOZART-4 was configured with a standard spatial resolution of grid cells with 28 sigma levels, which requires at least 2 GB of RAM per processor. Compilation of the code was carried out using the parallel mode OpenMP+MPI for the possibility of starting MOZART-4 on computing systems with shared and distributed memory. Results of the built model verification are presented in [9].

\section{MOZART-4 modification}

\subsection{Climatic data}

According to [8], the basic version of the MOZART-4 model uses data from the NCAR/NCEP reanalysis as input climatic fields. The climatic fields required for launching the model are shown in Table 1. However, the current version of the NCAR/NCEP reanalysis does not contain all the required fields.

The developers recommend using the meteorological fields from the Goddard Earth Observing System, Version 5 (GEOS-5) or Modern-Era Retrospective analysis for Research and Applications, Version 2 (MERRA-2) models [10]. However, the GEOS-5 and MERRA-2 data is represented with a spatial resolution of $144 \times 96$ grid cells with 56 sigma levels, which the base version of MOZART-4 does not support. For this reason, in the first stage of the study, on the base of the GEOS-5 model [11], climatic fields with a spatial resolution of $128 \times 64$ grid cells and 28 sigma levels were prepared. This was done using the netCDF Operators (NCO) package [12], which is designed to handle data presented in the netCDF format.

\subsection{Boundary conditions}

Methane is readily soluble in the atmosphere and its so-called "lifetime" is $12.6 \pm 3$ years, and the contribution of each source is difficult to estimate. Therefore, in the basic version of MOZART-4, 
Table 1

Meteorological inputs required for MOZART-4.

\begin{tabular}{cccc}
\hline Variable & MOZART-4 name & Dimension & Units \\
\hline Zonal Winds & $\mathrm{U}$ & $3 \mathrm{D}$ & $\mathrm{m} / \mathrm{s}$ \\
Meridional Winds & $\mathrm{V}$ & $3 \mathrm{D}$ & $\mathrm{m} / \mathrm{s}$ \\
Temperature & $\mathrm{T}$ & $3 \mathrm{D}$ & $\mathrm{K}$ \\
Specific Humidity (optional) & $\mathrm{Q}$ & $3 \mathrm{D}$ & $\mathrm{kg} / \mathrm{kg}$ \\
Surface Temperature & $\mathrm{TS}$ & 2D & $\mathrm{K}$ \\
Surface Pressure & PS & 2D & $\mathrm{Pa}$ \\
Land/Ocean/Sea Ice Flag & ORO & 2D & - \\
Surface Geopotential Height & PHIS & 2D & $\mathrm{m}^{2} / \mathrm{s}^{2}$ \\
Surface Zonal Stress & TAUX & 2D & $\mathrm{N}^{2} / \mathrm{s}^{2}$ \\
Surface Meridional Stress & TAUY & 2D & $\mathrm{N} / \mathrm{s}^{2}$ \\
Surface Heat Flux & SHFLX & 2D & $\mathrm{W} / \mathrm{m}^{2}$ \\
Surface Moisture Flux & QFLX & 2D & $\mathrm{Kg} /\left(\mathrm{m}^{2} \cdot \mathrm{s}\right)$ \\
Solar Flux at Surface & FSDS & 2D & $\mathrm{W} / \mathrm{m}^{2}$ \\
Snow Height & SNOWH & 2D & $\mathrm{m}$ \\
Soil Moisture Fraction & SOILW & 2D & - \\
Previous month's average TS & TSavg & 2D & $\mathrm{K}$ \\
Previous month's average FSDS & FSDSavg & 2D & $\mathrm{W} / \mathrm{m}^{2}$ \\
\hline
\end{tabular}

the boundary conditions for $\mathrm{CH}_{4}$ were specified using the values of the surface concentration. Sources of such gases as hydrogen $\left(\mathrm{H}_{2}\right)$ and nitrous oxide $\left(\mathrm{N}_{2} \mathrm{O}\right)$ were described similarly [8].

Thus, in the basic version of the model, the results of analysis made by Earth System Research Laboratories/Global Monitoring Laboratory of National Oceanic and Atmospheric Administration (ESRL/GMD NOAA) [13] were taken as the basis for defining the methane content, which are interpreted by the model as the zonal monthly average concentration in the cell on the $20 \times 20^{\circ}$ grid $[8,10]$. These data describe the period 1985-2007. In the current version of the model, the methane content is specified using the UMSLIMCAT model output from the World Meteorological Organization's (WMO) 2006 REF2 experiment [14].

The boundary conditions for the upper boundary of the atmosphere are indicated similarly. For stratospheric gases such as $\mathrm{O}_{3}, \mathrm{NOX}, \mathrm{HNO}_{3}, \mathrm{~N}_{2} \mathrm{O}_{5}, \mathrm{CO}, \mathrm{CH}_{4}$ in the base model MOZART-4, the grids of upper boundary conditions were calculated using the MOZART-3 model, since it more accurately describes the chemistry of components in the stratosphere $[8,10]$. At the level above $50 \mathrm{hPa}$, where was the limit of model calculations, therefore, climatic data was used.

The results of the REF2 experiment differ from the actual observations, and the zonal monthly average value of the $\mathrm{CH}_{4}$ concentration in a cell on a $20 \times 20^{\circ}$ grid does not allow describing local effects (we discuss this in detail in [9]). Therefore, the second step of the study was devoted to the modification of the boundary conditions for MOZART-4.

The initial material for the modification was the ESRL/GMD NOAA data [13] and the results of the Atmospheric Chemistry-Transport Models (ACTM) [15]for the period 2007-2010. The algorithm for constructing new boundary conditions included the following stages.

1. Using ESRL/GMD NOAA data, boundary conditions were interpolated with a spatial resolution of $2.8 \times 2.8^{\circ}$ for the period $1985-2020$. Note that this was a zonal monthly 


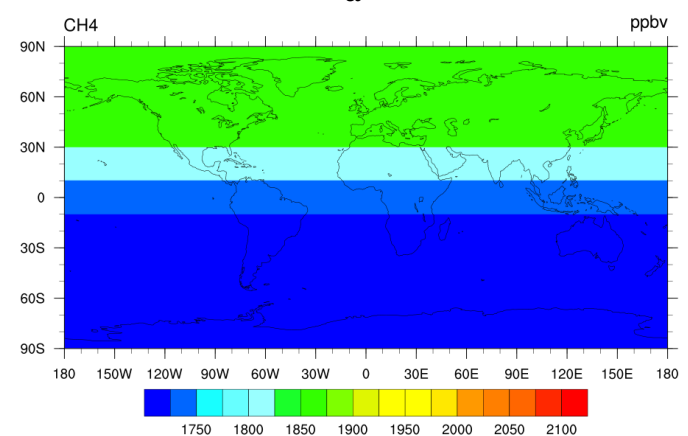

b

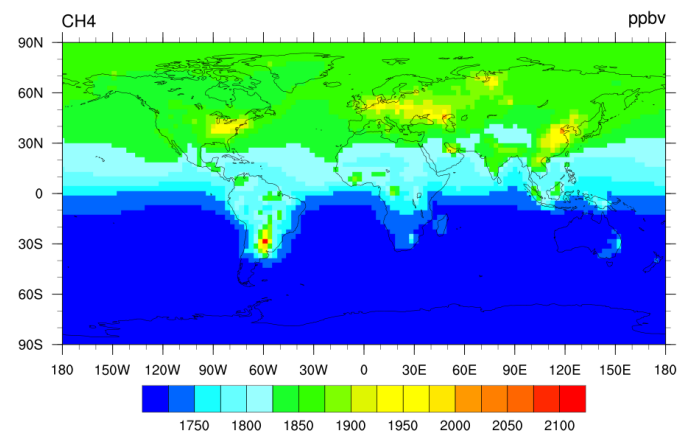

Figure 1: Spatial distributions of the monthly mean surface methane concentration in June 2007 (ppbv) for the original (a) and modified (b) boundary conditions.

average value of $\mathrm{CH}_{4}$ concentration.

2. For each cell of the resulting grid, using the ACTM data, the difference was found:

$$
m=\mathrm{CH}_{4}(\mathrm{ACTM})-\mathrm{CH}_{4}(\mathrm{ESRL}) \text {. }
$$

The operation was performed only for the period 2007-2010.

3. For the grid cell $2.8 \times 2.8^{\circ}$ and each month, the average value of $m$ was calculated for the period 2007-2010.

4. Using the obtained corrections $m$, the MOZART-4 boundary conditions for the period 1985-2020 were assembled.

Figure 1 shows the spatial distributions of the monthly mean surface methane concentration in June 2007 for the original (a) and modified (b) boundary conditions. It is clearly seen that the new data describe the sources of methane. In accordance with this approach, the boundary conditions were modified at the upper boundary of the modeling area.

\section{Results}

MOZART-4 simulation with new boundary conditions was carried out for the period 2000-2020. A version of the model with a spatial resolution of $128 \times 64$ cells with 28 sigma levels was used. The simulation was conducted on a multiprocessor computer with shared memory, the number of floating point operations of which is $\sim 2$ GFLOPS.

Refinement of the MOZART-4 boundary conditions made it possible to obtain good agreement with the data of the ACTM model, as well as with the ground-based observations [16]. Figure 2 shows the annual cycle of the total methane content in the atmosphere of Western Siberia (45-65 N, 60-90 E) for the period 2007-2009. It can be seen that, as a result of modification, MOZART-4 reproduces the summer and winter maxima, which are typical for satellite measurements [10]. Note that these local effects are not reproduced in the basic version of the model. 


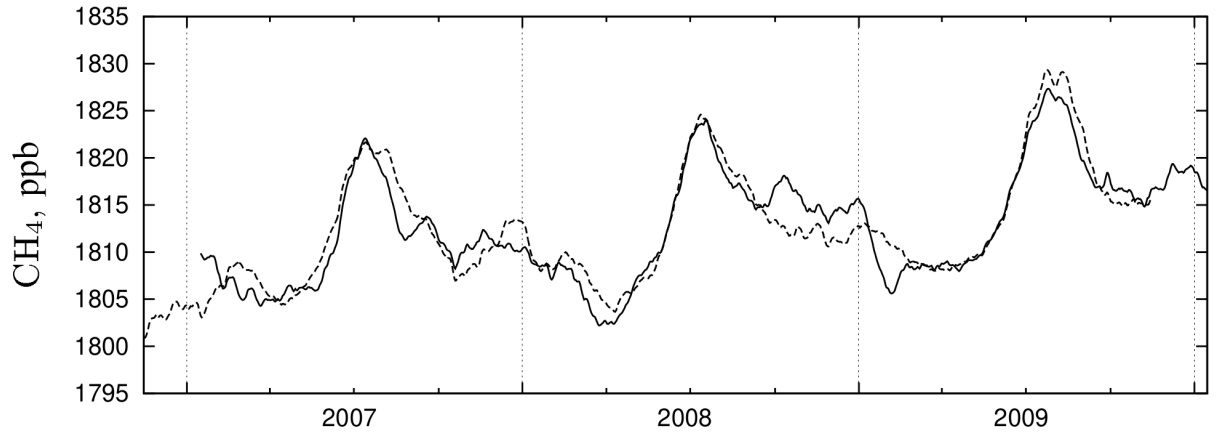

Figure 2: Annual and seasonal changes in the total methane content in the atmosphere of Western Siberia. In the figure, the solid line is the ACTM data, the dashed line is the MOZART-4 data with modified boundary conditions.

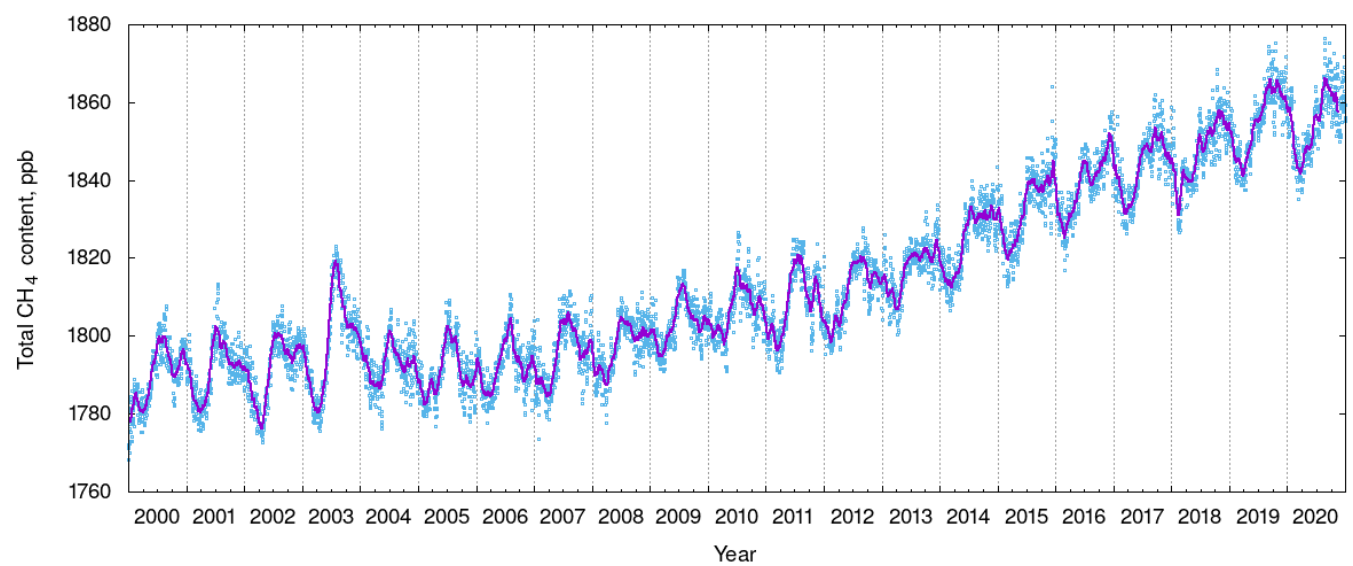

Figure 3: Annual cycle and interannual variability of total methane content in the atmosphere of Western Siberia.

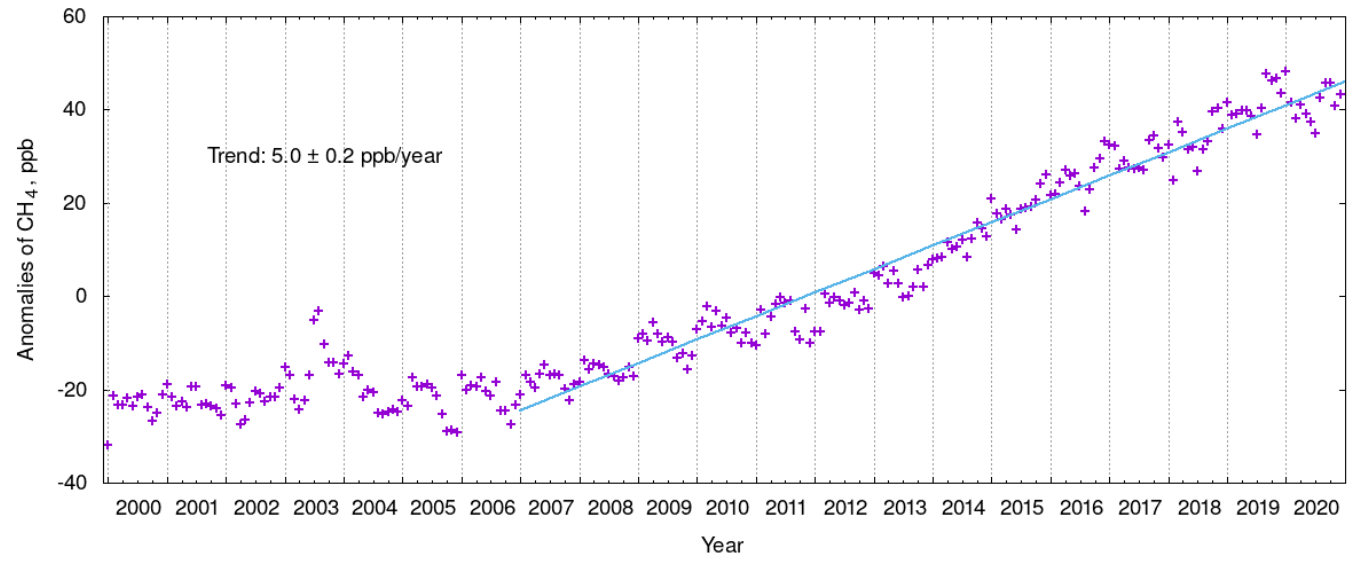

Figure 4: Anomalies of total methane content in the atmosphere of Western Siberia. 
The behavior of the total methane content during the entire considered period 2000-2020 is illustrated in Figure 3. Here, the dots show the zone-averaged daily $\mathrm{CH}_{4}$ values, and the line shows the 30-day moving average. One can see that the summer and winter maxima of the methane content in the atmosphere, which are distinctive for Western Siberia, are reproduced over the entire investigated period of time.

The analysis of the total methane content anomalies obtained using the approach [17] and shown in Figure 4 allows us to establish that the increase of $\mathrm{CH}_{4}$ in 2007-2020 had a trend of $\sim 5.0 \pm 0.2 \mathrm{ppb} /$ year. In 2000-2006, there was virtually no trend, which corresponds to the stationary state of methane in the atmosphere, which was observed in 1996-2006 [18]. For the whole period researched, the increase of $\mathrm{CH}_{4}$ in Western Siberia has a trend of $\sim 3.5 \pm 0.2 \mathrm{ppb} /$ year. It should be noted that the result is in good agreement with the estimates obtained from satellite observations for the territory of Western Siberia for 2003-2018 [19].

\section{Discussion}

We acknowledge that the obtained result requires additional validation using observations carried out in other climatic zones. The source of such information can be, for example, data received by the Total Carbon Column Observing Network (TCCON) [20].

Another important remark is that the spatial distribution of surface methane according to ACTM data is not valid for the entire period 2000-2020. However, this approach makes it possible to describe local effects better than latitude-averaged data do.

Also, mention should be made of other assumptions used in the model. The tropopause altitude and solar activity are specified as monthly mean annual estimations, and the concentration of substances chemically associated with methane needs to be specified.

The low spatial resolution of the model and the method used to set the methane emission do not allow a complete description of the local effects. However, the global data obtained as a result of simulation can be used as the initial and boundary conditions for the chemical version of the regional climate model RegCM-CHEM4 [21].

The next stage of the study is setting up an experiment to simulate the behavior of methane up to 2050 within the global scenarios RCP4.5 and RCP8.5. The input data of the Community Atmosphere Model with Chemistry (CAM-chem) [22] can be used in accordance with the technology used in the work and used to set the boundary conditions. Another important task is the search and preparation of climatic fields for modeling MOZART-4 until 2050.

Since the development and support of the MOZART-4 project is discontinued [10], the authors do not rule out the use of the CAM-chem model for further research. It should be noted that CAM-chem uses the MOZART chemical mechanism [22], with various choices of complexity for tropospheric and stratospheric chemistry.

\section{Conclusion}

The work was devoted to the investigation of the behavior of the total methane content in the atmosphere of Western Siberia in 2000-2020 using the chemical transport model MOZART-4. In the course of the study, the following results were obtained: 
1. Climatic data were prepared for working with MOZART-4 for 2000-2020 using the results of the GEOS-5 model. The new boundary conditions were prepared for describing the methane content in the surface air layer and in the stratosphere. The results for 2007-2010 of the ACTM model and the ESRL/GMD NOAA data were used.

2. Modification of the boundary conditions, that had been carried out in the work, made it possible to reproduce the summer and winter maximum in the annual cycle of $\mathrm{CH}_{4}$, which was confirmed by satellite and aircraft observations made on the territory of Western Siberia.

3. The total methane content in the atmosphere of the studied region (45-65 N, 60-90 E) in 2000-2020 has increased with a trend of $\sim 3.5 \pm 0.2 \mathrm{ppb} /$ year, which is confirmed by satellite estimate made in the territory of Western Siberia for the 2003-2018 period [19]. In 2000-2006, there was virtually no trend. The increase of $\mathrm{CH}_{4}$ in $2007-2020$ has a trend of $\sim 5.0 \pm 0.2 \mathrm{ppb} /$ year.

\section{Acknowledgments}

The study was carried out within the framework of the Program for the support of scientific and pedagogical workers of the Altai State University, the project "Assessment of greenhouse gas emissions by oil industry enterprises in Western Siberia according to satellite observations and modeling”.

\section{References}

[1] P. R. Shukla, Climate Change and Land: an IPCC special report on climate change, desertification, land degradation, sustainable land management, food security, and greenhouse gas fluxes in terrestrial ecosystems. IPCC, 2019. URL: http://www.ipcc.ch/site/assets/uploads/ 2019/11/SRCCL-Full-Report-Compiled-191128.pdf.

[2] G. A. Zavarzin, Mikrobnyy tsikl metana v kholodnykh usloviyakh, Priroda 6 (1995) 3-14 (in Russian).

[3] M. Y. Arshinov, B. D. Belan, D. K. Davydov et al., Vertical distribution of greenhouse gases above Western Siberia by the long-term measurement data, Atmos. Ocean. Opt. 22 (2009) 316-324. doi:10.1134/S1024856009030087.

[4] M. V. Glagolev, New Russian research of methane emission from bog ecosystems of the northern Western Siberia, Environmental dynamics and global climate change 4 (2013) EDCCbrv0005 (in Russian).

[5] M. V. Glagolev, A. F. Sabrekov, I. E. Kleptsova et al., Methane Emission from Bogs in the Subtaiga of Western Siberia: The Development of Standard Model, Eurasian Soil Sci. 45 (2012) 947-957. doi:10.1134/S106422931210002X.

[6] G. K. Heilig, The greenhouse gas methane (CH4): Sources and sinks, the impact of population growth, possible interventions, Population and Environment 16 (1994) 109137.

[7] S. Kirschke, P. Bousquet, P. Ciais et al., Three decades of global methane sources and sinks, Nature Geoscience 6 (2013) 813-823. doi:10 . 1038/ngeo1955. 
[8] L. K. Emmons, S. Walters, P. G. Hess et al., Description and evaluation of the Model for Ozone and Related chemical Tracers, version 4 (MOZART-4), Geosci. Model Dev. 3 (2010) 43-67. doi:10 . 5194/gmd-3-43-2010.

[9] E. Y. Mordvin, A. A. Lagutin, Methane in the atmosphere of Western Siberia, Azbuka, Barnaul, 2016. (in Russian).

[10] Atmospheric chemistry observations \& modeling. national center for atmospheric research. mozart-4, ???? URL: http://www2.acom.ucar.edu/gcm/mozart-4.

[11] S. Tilmes, GEOS5 Global Atmosphere Forcing Data. Research Data Archive at the National Center for Atmospheric Research, Computational and Information Systems Laboratory., 2006. URL: http://doi.org/10.5065/QTSA-G775.

[12] Bienvenue sur le netCDF Operator (NCO) site, (Lastaccessed July 25, 2021). URL: http: //nco.sourceforge.net/.

[13] Earth System Research Laboratories. Global Monitoring Laboratory., (Lastaccessed July 25, 2021). URL: http://gml.noaa.gov/ccgg/mbl/data.php.

[14] M. Chipperfield, W. Tian, CCMVal-1: University of Leeds UMSLIMCAT model output contribution to the WMO 2006 REF2 experiment, NCAS British Atmospheric Data Centre, 2014. URL: https://catalogue.ceda.ac.uk/uuid/85848d8879bf9aea8b08aa24c97c0850.

[15] R. Saito, P. K. Patra, N. Deutscher et al., Technical Note: Latitude-time variations of atmospheric column-average dry air mole fractions of $\mathrm{CO} 2, \mathrm{CH} 4$ and N2O, Atmos. Chem. Phys. 12 (2012) 7767-7777. doi:10 . 5194/acp-12-7767-2012.

[16] M. Sasakawa, A. Ito, T. Machida, Annual variation of $\mathrm{CH} 4$ emissions from the middle taiga in West Siberian Lowland (2005-2009): a case of high CH4 flux and precipitation rate in the summer of 2007, Tellus B.: Chemical and Physical Meteorology 64 (2012) 17514.

[17] N. N. Shchelkanov, Obobshchennyj metod postroeniya linejnoj regressii i ego primenenie dlya postroeniya odnoparametricheskih modelej aerozolnogo oslableniya, Optics of the atmosphere and ocean 18(1-2) (2005) 86-90. (in Russian).

[18] E. J. Dlugokencky, L. Bruhwiler, J. W. C. White et al., Observational constraints on recent increases in the atmospheric $\mathrm{CH} 4$ burden, Geophys. Res. Lett. 36 (2009).

[19] E. Mordvin, A. Lagutin, N. Volkov et al., Methane in the atmosphere of Western Siberia: results of satellite observations and simulations, CEUR Workshop Proceedings 2534 (2020) 418-422.

[20] D. Wunch, G. C. Toon, J. F. L. Blavier et al., The Total Carbon Column Observing Network, Phil. Trans. R. Soc. A. 369 (2011) 2087-2112.

[21] A. Shalaby, A. S. Zakey, A. Tawfik et al., Implementation and evaluation of online gas-phase chemistry within a regional climate model (RegCM-CHEM4), Geosci. Model Dev. 5 (2012) 741-760.

[22] J. F. Lamarque, L. Emmons, P. Hess et al., CAM-chem: Description and evaluation of interactive atmospheric chemistry in the Community Earth System Model, Geosci. Model Dev. 5 (2012) 369-411. 